\title{
Relative Performance of Strawberry Genotypes over Four Cycles of Cultivation on Fumigated and Nonfumigated Soils
}

\author{
Douglas V. Shaw and Kirk D. Larson \\ Pomology Department, University of California, Davis, CA 95616
}

AdDitIONAL INDEX wORDS. chloropicrin, Fragaria $\times$ ananassa, genetic $\times$ fumigation interaction, methyl bromide.

\begin{abstract}
Yield and fruit size were determined for 49 strawberry (Fragaria $\times$ ananassa Duch.) genotypes during a 7 year period, in soils prepared with and without preplant soil fumigation using 2 methyl bromide : 1 chloropicrin (wt/wt). Strawberries were grown in alternate years, with the nonfumigated treatment representing the first, second, third, and fourth strawberry crop cycles initiated without soil fumigation. Highly significant $(P<0.01)$ effects of soil fumigation treatment were present for yield in a combined analysis over all years; fumigation increased yield by $41 \%$ over nonfumigated soils in the first nonfumigated cultivation cycle and by $68 \%$ to $74 \%$ for subsequent nonfumigated cycles. Fruit size was less affected by soil treatment but increases due to fumigation $(2 \%$ to $18 \%)$ were significant $(P<0.05)$ in the third or fourth nonfumigated crop cycle. Genotypic variances were highly significant in the combined analysis, whereas genetic $\times$ fumigation interaction variances were significant only for fruit size and contributed $<8 \%$ of the total phenotypic variance for either trait. Genetic correlations were $r_{\mathrm{g}}=0.77$ and 0.92 , respectively, for yield and fruit size treated as independent traits across soil fumigation environments. There was no evidence for genes that confer specific adaptation to nonfumigated soils, or that these genes emerge as important contributors to the phenotypic variation as the soil environment deteriorates with repeated cultivation of strawberry in nonfumigated soil. Chemical names used: trichloronitromethane (chloropicrin).
\end{abstract}

Reports published during the past 50 years have documented the benefits of preplant soil fumigation with a mixture of methyl bromide and chloropicrin for annual (Wilhelm et al., 1974; Wilhelm and Paulus, 1980) and perennial strawberry (Fragaria $\times$ ananassa) production systems (Hancock et al., 2000). Recent research syntheses have shown that yield differences between plants cultivated in fumigated and nonfumigated soils increase over cycles of strawberry cultivation (Shaw and Larson, 1999). The increasing benefits of soil fumigation over time resulted from deterioration of soil environments with repeated cropping of strawberry in the absence of fumigation, rather than from accrued benefits of repeat fumigation. This pattern must be viewed as a substantial obstacle to successful strawberry cultivation in annual systems without soil fumigation.

Although breeding and subsequent development of specially adapted cultivars is cited frequently as an alternative to preplant soil fumigation for strawberry (USDA, 1993; Watson et al., 1992), studies published to date have demonstrated a virtual absence of genetic variance for specific adaptation to the sublethal soil organisms that affect strawberry performance. This general absence of soil-specific adaptive variation is evidenced by the nonsignificant genetic $\times$ fumigation interactions found in California germplasm for production traits (Fort and Shaw, 2000 b; Fort et al., 1996; Larson and Shaw, 1995) and root characteristics (Fort and Shaw, 2000a). Soil-specific adaptive variation was also absent in studies that included other North American germplasm sources of $F$. ×ananassa (Shaw and Larson, 1996), and when fumigation responses were evaluated in perennial strawberry cultural systems (Hancock et al., 2000). These findings are consistent with genetic interaction results in general, where substantial rank-shift interactions are usually accompanied by the presence or absence of a specific lethal plant pathogen

Received for publication 30 May 2000. Accepted for Publication 10 Oct. 2000. The cost of publishing this paper was defrayed in part by the payment of page charges. Under postal regulations this paper must be hereby marked advertisement solely to indicate this fact. and rather discretely inherited resistance classes in the crop evaluated (Baker, 1988).

One question that has not been addressed to date for strawberry is whether the absence of genetic variation for specific adaptation to the sublethal consequences of nonfumigated soils will be consistent as soils deteriorate due to repeated cropping cycles without preplant fumigation. Differing and increasingly substandard soil environments generated through repeated cropping without fumigation could expose genetic variation that is cryptic in the first cultivation cycle after repeated intervals of fumigation and crop production. Therefore, the objective of our study was to extend the prior search (Larson and Shaw, 1995) for soil-specific adaptive variation by using a larger sample of strawberry genotypes, and most importantly to examine any changes that might occur in the distribution of genetic and genetic $\times$ fumigation interaction variances as the nonfumigated soil environments deteriorate over repeated strawberry cultivation cycles.

\section{Materials and Methods}

All performance trials were conducted at the University of California Strawberry Research Facility, near Watsonville in the central coast of California (lat. 36 $54^{\prime} \mathrm{N}$, long. $121^{\circ} 48^{\prime} \mathrm{W}$ ). Two subsites separated by approximately $50 \mathrm{~m}$ were used at this location, with strawberry trials conducted in 1993, 1995, 1997, and 1999 at one subsite, and in 1994, 1996, and 1998 at the second. For each subsite the initial nonfumigated cultivation cycle reported herein (i.e., 1993 and 1994) was established on soil that had been cropped in strawberry in alternate years during the prior 12 years. Each of the six previous strawberry cultivation cycles was preceded by a cover crop of barley (Hordeum vulgare L.) and broad bean (Vicia faba L.), and strawberry crops were grown after preplant soil fumigation using 2 methyl bromide: 1 chloropicrin (wt/wt), at 303 to $392 \mathrm{~kg} \cdot \mathrm{ha}^{-1}$. Fumigation treatments for each of the seven current trials were applied by preparing adjacent parcels within a subsite for planting and either 
treating with 2 methyl bromide: 1 chloropicrin (wt/wt), at 392 $\mathrm{kg} \cdot \mathrm{ha}^{-1}$, or leaving the soil untreated. Parcels initially chosen as nonfumigated received no soil fumigation throughout all seven trial years. The alternate-year system of strawberry cultivation was continued for each crop of strawberry, and each of our seven trials was preceded by a cover crop of barley and broad bean, regardless of its preplant soil treatment.

Runner plants from 49 strawberry genotypes were used during the seven trial years. Thirty-five of the genotypes were tested in more than one year, and seven of the genotypes were tested in four or more years. The 49 genotypes were chosen from the current cultivars and advanced selections available from University of California (U.C.) strawberry improvement program. Fourteen of the genotypes were (or eventually were released as) cultivars and 25 were advanced selections not released to date. Twenty of the genotypes were day-neutral and the remainder were extendedfruiting short-day flowering types with a range of production patterns. These genotypes thus comprise an extensive and representative sample of the current elite germplasm available for breeding purposes within the U.C. program.

Trials were established and treated according to recommendations for annual commercial winter planting systems (Welch, 1989). Runner plants for all trails were harvested each year from a propagation nursery near Macdoel, Calif. (lat. $41^{\circ} 45^{\prime} \mathrm{N}$, long. $\left.121^{\circ} 59^{\prime} \mathrm{W}\right)$ on 15 to 17 Oct. For the 1993 trial, all genotypes were planted on 21 Oct., 1992. For all other trials, short-day genotypes were established after 5 to $8 \mathrm{~d}$ and day-neutral genotypes after 21 to $28 \mathrm{~d}$ of supplemental cold storage at $1{ }^{\circ} \mathrm{C}$, consistent with recommendations for optimizing their performance in annual production systems (Strand, 1994). Experimental plots were established on two-row beds with $1.32-\mathrm{m}$ centers and $0.36-\mathrm{m}$ inrow plant spacing. Two replicates were established within each soil treatment, with a single plot of 20 runner plants per genotype in each replication.

Fruit yield and fresh weight of a 10 fruit sample were recorded weekly, for 23 to 27 consecutive weeks during the spring and summer following planting in each trial year. Total yield was evaluated for each plot on a per-plant basis, and fruit size was calculated as the weighted average of the weekly 10-fruit sample weights obtained throughout the season, with weighting based on corresponding weekly yield. All results were tested for scale effects but no transformation was required prior to further analyses (Fernandez, 1992). Analyses of variance (ANOVA) for each trait were performed in a joint analysis with soil fumigation treatment as a fixed effect, years and genotypes as random effects; replications were nested in years and fumigation treatments. Analyses were conducted using SAS procedure GLM (SAS Inst, Inc., 1988) and significance tests were performed using type III expected mean squares (Table 1). Model variance components due to genotypes $\left(\sigma_{\mathrm{g}}^{2}\right)$, genotype $\times$ year interaction $\left(\sigma_{\mathrm{yg}}^{2}\right)$, genotype $\times$ fumigation treatment interaction $\left(\sigma_{\mathrm{fg}}^{2}\right)$, genotype $\times$ year $\times$ fumigation interaction $\left(\sigma_{\text {ygf }}^{2}\right)$, and error $\left(\sigma^{2}\right)$ were estimated by equating the expected mean squares in Table 1 with their corresponding experimental mean squares, and solving this series of linear equations.

The extent to which the experimental phenotypic variance was explained by genotypic differences was quantified as the experimental repeatability:

$\mathrm{R}=\sigma_{\mathrm{g}}^{2} /\left(\sigma_{\mathrm{g}}^{2}+\sigma_{\mathrm{yg}}^{2}+\sigma_{\mathrm{fg}}^{2}+\sigma_{\mathrm{yfg}}^{2}+\sigma^{2}\right)$

Repeatability, R, in Eq. [1] is analogous to a plot-mean genotypic heritability, except that genetic components of variance were estimated for a population that has been selected and not recombined through random mating (Larson and Shaw, 1995; Shaw, 1992). The similarity of genotypic responses between the two fumigation treatments was quantified by treating individual traits in different fumigation treatments as separate but genetically correlated, and estimating their genotypic correlation as (Burdon, 1977):

$r_{\mathrm{g}}=\sigma_{\mathrm{g}}^{2} /\left(\sigma_{\mathrm{g}}^{2}+\sigma_{\mathrm{fg}}^{2}+\sigma_{\text {yfg }}^{2}\right)$

This genotypic correlation can be used to predict the correspondence in genetic selection response, where selection is conducted in one soil fumigation environment and performance is tested in the other.

Because fumigation treatments were established on the same parcels within each subsite in alternate years, the fumigation response, or difference between fumigated and nonfumigated treatments for each trait, could be evaluated for different nonfumigated crop cycles. Trials conducted in 1993 and 1994 represent the first strawberry crop in 12 seasons initiated without the use of preplant soil fumigation; nonfumigated treatments for 1995 and 1996 trials represent the second strawberry crop produced without fumigation, 1997-99 nonfumigated treatments represent plantations in the third or fourth cultivation cycle established without preplant soil fumigation. The significance and magnitude of fumigation, genotypic, and interaction variances were compared over these cultivation cycles to evaluate trends in genetic and genetic $\times$ fumigation interaction effects as soil environments deteriorate due to repeated cropping of strawberry without preplant fumigation. ANOVAs for this comparison were conducted after segregating the individual-year results into three sets that represent comparisons in the first, second, or thirdor-greater cycle of cultivation in nonfumigated soil. Statistical evaluations for these three sets were made using the expected mean squares in Table 2. For this analysis, the effects of years and associated interactions were ignored, due to confounding of genetic $\times$ year and genetic $\times$ replication-in-year effects. The main effects of years is reflected in the replicates-in-fumigation term, and year $\times$ fumigation interactions are pooled in the error term. Repeatabilities and cross-soil type genetic correlations were estimated as in Eqs. [1] and [2], except that interaction terms involving years were not included.

\section{Results and Discussion}

Yield and fruit size were greater for plants grown in fumigated soils than for plants grown in nonfumigated soils for each of the seven trial years (Table 3). Over all years, yield and fruit size for plants in fumigated soils $(1603 \pm 24.9 \mathrm{~g} /$ plant and $27.9 \pm 0.28 \mathrm{~g} /$ fruit, respectively) exceeded those for nonfumigated soils ( $993 \pm$ $25.3 \mathrm{~g} / \mathrm{plant}$ and $25.8 \pm 0.20 \mathrm{~g} /$ fruit, respectively) by $61 \%$ and $8 \%$, respectively. The main effects of preplant soil fumigation were highly significant $(P<0.01)$ for both traits (Table 4$)$. Year $\times$ fumigation treatment interaction variances were highly significant for both traits, indicating a failure of the fumigation treatment to provide similar levels of response across years; these interaction variances may reflect changes in the nonfumigated soil environment over repeated cultivation cycles, although substantial variation for percentage increase exists within cycles as well (Table 4).

Yields for individual genotypes ranged from 607 to $2120 \mathrm{~g} /$ plant in fumigated soils, and from 326 to $1415 \mathrm{~g} / \mathrm{plant}$ in nonfumigated soils. Genotypic means for fruit size were 21.7 to 35.5 and 21.3 to $30.5 \mathrm{~g} /$ fruit for the same soil types, respectively. The precision of trait means for individual genotypes varied in 
Table 1. Expected means squares for analysis of variance of seasonal strawberry yield and average fruit size over 7 years in fumigated and nonfumigated soils.

\begin{tabular}{lcl}
\hline \hline Source & $\mathrm{df}$ & Expected mean squares \\
\hline Year $(\mathrm{Y})$ & 6 & $\sigma^{2}+2 \sigma_{\mathrm{yfg}}^{2}+13.3 \sigma_{\mathrm{yf}}^{2}+6.7 \sigma_{\mathrm{r}}^{2}+4 \sigma_{\mathrm{yg}}^{2}+26.7 \sigma_{\mathrm{y}}^{2}$ \\
Fumigation $(\mathrm{F})$ & 1 & $\sigma^{2}+2 \sigma_{\mathrm{yfg}}^{2}+18.0 \sigma_{\mathrm{yf}}^{2}+9.0 \sigma_{\mathrm{r}}^{2}+2.8 \sigma_{\mathrm{fg}}^{2}+125.7 \sigma_{\mathrm{f}}^{2}$ \\
Y $\times \mathrm{F}$ & 6 & $\sigma^{2}+2 \sigma_{\mathrm{yfg}}^{2}+13.3 \sigma_{\mathrm{yf}}^{2}+6.7 \sigma_{\mathrm{r}}^{2}$ \\
Replication/(Y $\times \mathrm{F})$ & 14 & $\sigma^{2}+12.7 \sigma_{\mathrm{r}}^{2}$ \\
Genotype $(\mathrm{G})$ & 48 & $\sigma^{2}+2 \sigma_{\mathrm{yfg}}^{2}+4 \sigma_{\mathrm{yg}}^{2}+3.4 \sigma_{\mathrm{fg}}^{2}+6.8 \sigma_{\mathrm{g}}^{2}$ \\
$\mathrm{Y} \times \mathrm{G}$ & 34 & $\sigma^{2}+2 \sigma_{\mathrm{yfg}}^{2}+4 \sigma_{\mathrm{yg}}^{2}$ \\
F $\times \mathrm{G}$ & 48 & $\sigma^{2}+2 \sigma_{\mathrm{yfg}}^{2}+3.4 \sigma_{\mathrm{fg}}^{2}$ \\
$\mathrm{Y} \times \mathrm{F} \times \mathrm{G}$ & 34 & $\sigma^{2}+2 \sigma_{\mathrm{yfg}}^{2}$ \\
Error & 164 & $\sigma^{2}$ \\
\hline
\end{tabular}

Table 2. Expected means squares for analysis of variance of seasonal strawberry yield and average fruit size over three cultivation cycles in fumigated and nonfumigated soils.

\begin{tabular}{lcl}
\hline \hline Source & $\mathrm{df}$ & Expected mean squares \\
\hline Fumigation $(\mathrm{F})$ & 1 & $\sigma^{2}+\mathrm{k}_{1} \sigma_{\mathrm{fg}}^{2}+\mathrm{k}_{2} \sigma_{\mathrm{r}}^{2}+\mathrm{k}_{3} \sigma_{\mathrm{f}}^{2}$ \\
Replication/(F) & 14 & $\sigma^{2}+\mathrm{k}_{4} \sigma_{{ }_{\mathrm{r}}}^{2}$ \\
Genotype $(\mathrm{G})$ & 48 & $\sigma^{2}+\mathrm{k}_{5} \sigma_{\mathrm{fg}}^{2}+\mathrm{k}_{6} \sigma_{\mathrm{g}}^{2}$ \\
F $\times \mathrm{G}$ & 48 & $\sigma^{2}+\mathrm{k}_{\mathrm{7}} \sigma_{\mathrm{fg}}^{2}$ \\
Error & 164 & $\sigma^{2}$
\end{tabular}

$\overline{{ }^{\mathrm{z}} \mathrm{k}_{1}=2.2,2.3 \text {, and } 1.4, \mathrm{k}_{2}=11.1,10.9 \text {, and } 5.9, \mathrm{k}_{3}=44.4,43.8 \text {, and } 35.6}$, $\mathrm{k}_{4}=9.3,9.7$, and $11.4, \mathrm{k}_{5}=2.3,2.4$, and $3.2, \mathrm{k}_{6}=4.6,4.9$, and 6.3 , and $\mathrm{k}_{7}=2.3,2.4$, and 3.2 for experiments where the nonfumigated treatment represents the first, second or third cycles of nonfumigated strawberry cultivation.

this experiment due to differential representation over years; variance components estimated for the combined set provide measures of genotypic dispersion unbiased by year effects and replication number, thus genotypic means were not considered further. The genotypic variance was the largest single component of the phenotypic variance in the combined analysis for both traits, $\mathrm{R}=0.45$ and 0.80 for yield and fruit size, respectively (Table 4). Genetic $\times$ fumigation interactions were statistically significant $(P<0.05)$ only for fruit size, and genetic $\times$ fumigation $\times$ year interactions were not statistically significant. All interaction variances were small relative to genotypic variances (Table 4) and cross-soil treatment genetic correlations were consequently large $\left(r_{\mathrm{gy}}=0.77-0.91\right)$ in this combined analysis. The cross-soil treatment genotypic correlations estimated here are nearly identical in magnitude to those reported previously (Larson and Shaw, 1995), despite the inclusion in this analysis of genetic $\times$ fumigation $\times$ year interaction sources. Large three-way interactions might indicate a change in the expression of genetic variance resulting from deteriorating soil conditions in the nonfumigated environments, i.e., over cultivation cycles, but evidence for this is lacking in our results.

Differences in yield and fruit size between soil treatments increased after the first cycle of strawberry cultivation on

Table 3. Means and standard deviations for seasonal strawberry yield and average fruit size over 7 years in fumigated and nonfumigated soils.

\begin{tabular}{|c|c|c|c|c|c|}
\hline $\begin{array}{l}\text { Test } \\
\text { year }\end{array}$ & $\begin{array}{l}\text { Cycle }^{z} \\
\text { (mean) }\end{array}$ & $\begin{array}{l}\text { Fumigation } \\
\text { treatment }^{y}\end{array}$ & $\mathrm{n}$ & $\begin{array}{c}\text { Yield } \\
\text { (g/plant) }\end{array}$ & $\begin{array}{c}\text { Fruit size } \\
\text { (g/fruit) }\end{array}$ \\
\hline \multirow[t]{2}{*}{1993} & 1 & - & 24 & $752(173)$ & $24.3(2.9)$ \\
\hline & & + & 24 & $1480(359)$ & $26.1(3.2)$ \\
\hline \multirow[t]{4}{*}{1994} & 1 & - & 24 & $1521(337)$ & $25.6(2.1)$ \\
\hline & & + & 24 & 1719 (377) & $25.9(2.3)$ \\
\hline & $\bar{X}_{\text {Cycle } 1}$ & - & 48 & $1136(470)$ & $25.0(2.5)$ \\
\hline & & + & 48 & 1599 (384) & $26.0(2.8)$ \\
\hline \multirow[t]{2}{*}{1995} & 2 & - & 24 & $792(157)$ & $26.1(2.7)$ \\
\hline & & + & 24 & $1602(276)$ & $25.7(2.1)$ \\
\hline \multirow[t]{4}{*}{1996} & 2 & - & 24 & $1058(229)$ & $24.5(2.7)$ \\
\hline & & + & 24 & $1627(285)$ & $25.7(2.9)$ \\
\hline & $\bar{X}_{\text {Cycle 2 }}$ & - & 48 & 925 (236) & $25.3(2.8)$ \\
\hline & & + & 48 & $1614(278)$ & $25.7(2.5)$ \\
\hline \multirow[t]{2}{*}{1997} & 3 & - & 12 & $920(305)$ & $23.7(1.7)$ \\
\hline & & + & 12 & $1585(330)$ & $27.7(1.7)$ \\
\hline \multirow[t]{2}{*}{1998} & 3 & - & 24 & $1090(205)$ & $26.7(2.0)$ \\
\hline & & + & 24 & $1687(212)$ & $29.3(2.7)$ \\
\hline \multirow[t]{4}{*}{1999} & 4 & - & 46 & $884(258)$ & $27.2(2.3)$ \\
\hline & & + & 46 & 1557 (344) & $31.5(3.2)$ \\
\hline & $\overline{\mathrm{X}}_{\text {Cycle 3-4 }}$ & - & 82 & $950(265)$ & $26.5(2.4)$ \\
\hline & & + & 82 & $1599(311)$ & $30.3(3.2)$ \\
\hline
\end{tabular}

${ }^{\mathrm{z}}$ Number of intervening strawberry crops since the last broadcast fumigation treatment for nonfumigated treatments.

$\mathrm{y}_{(-)}$and (+) indicate no soil fumigation and preplant soil fumigation with $392 \mathrm{~kg} \cdot \mathrm{ha}^{-1}$ of 2 methyl bromide : $1 \mathrm{chloropicrin}$ (wt/wt), immediately before the current planting. 
Table 4. Results for analysis of variance for seasonal strawberry yield and average fruit size over 7 years in fumigated and nonfumigated soils.

\begin{tabular}{lcc}
\hline & \multicolumn{2}{c}{ Mean squares } \\
\cline { 2 - 3 } Source & \multicolumn{1}{c}{ Yield $^{\mathrm{z}}$} & Fruit size \\
\hline Year(Y) & $1369.1^{*}$ & 19.1 \\
Fumigation(F) & $22,733.1^{* *}$ & $262.0^{* *}$ \\
$\mathrm{Y} \times \mathrm{F}$ & $286.7^{* *}$ & $13.1^{* *}$ \\
Replication/(Y $\times \mathrm{F})$ & $49.4^{*}$ & $4.1^{* *}$ \\
Genotype $(\mathrm{G})$ & $321.7^{* *}$ & $34.4^{* *}$ \\
$\mathrm{Y} \times \mathrm{G}$ & $125.5^{* *}$ & $4.1^{* *}$ \\
$\mathrm{~F} \times \mathrm{G}$ & 46.9 & $3.0^{*}$ \\
$\mathrm{Y} \times \mathrm{F} \times \mathrm{G}$ & 28.7 & 1.7 \\
Error & 23.6 & 1.6 \\
$\sigma^{2}$ & 26.17 & 4.25 \\
$\sigma_{\mathrm{g}}^{2}$ & 24.21 & 0.61 \\
$\sigma_{\mathrm{gg}}^{2}$ & 5.35 & 0.37 \\
$\sigma_{\mathrm{fg}}^{2}$ & 2.56 & 0.06 \\
$r_{\mathrm{gy}}$ & 0.77 & 0.91 \\
$\mathrm{R}$ & 0.45 & 0.80 \\
\hline
\end{tabular}

${ }^{\mathrm{z}}$ Mean squares and variance components for yield in thousands.

${ }^{*}, * *$ Significant at $P<0.05$ or 0.01 , respectively.

nonfumigated soil (Table 3). Plants grown in fumigated soil yielded $41 \%$ more fruit than plants in nonfumigated soils in the first nonfumigated cultivation cycle, $74 \%$ more fruit compared with plants in the second nonfumigated cycle, and $68 \%$ more than plants grown in the third or greater nonfumigated cycles. Fruit size was less affected by soil fumigation than fruit yield (increases of $2 \%$ to $18 \%$ ), with the largest fumigation treatment effects expressed in the third or fourth strawberry crop cycle without preplant fumigation. The main effects of fumigation were highly significant for yield regardless of nonfumigated cultivation cycle; soil fumigation increased fruit size significantly only when the third or later cycle of nonfumigated cultivation was evaluated (Table 5). This pattern suggests that traits not initially identified as problematic in nonfumigated soils may be affected over time.

Highly significant genotypic variances were detected for both traits in all three of the sets generated based on the nonfumigated cultivation cycle (Table 5), and repeatabilities were large for both traits regardless of soil fumigation history $(\mathrm{R}=0.48-0.79)$. Genetic $\times$ fumigation interaction variances were statistically significant only for fruit size in the third-or-greater nonfumigated cultivation cycle and the interactions in this case comprised a very small fraction of the phenotypic variance (8.2\%). Cross-soil treatment genetic correlations were somewhat larger on average for both yield $\left(\overline{r_{\mathrm{gy}}}=0.92\right)$ and fruit size $\left(\overline{r_{\mathrm{gy}}}=0.95\right)$ than those derived from the combined analysis $\left(\overline{r_{\mathrm{gy}}}=0.77\right.$ and 0.91 for yield and fruit size, respectively, Table 4). Again, there is no evidence that genetic variation specific for adaptation to nonfumigated soils is expressed in larger fractions as soils deteriorate over cycles of nonfumigated strawberry cultivation.

Over time strawberry growers will face two obstacles to successful cultivation in nonfumigated soils: 1) reductions in yield and other performance characters resulting from increased damage and competition from sublethal soil organisms, and 2) increased plant mortality resulting from increased incidence of lethal pests and pathogens. To date, lethal pathogens have had a minimal impact on nonfumigated strawberry cultivation, in part because all commercial plantings use stock from fumigated nurseries. The consequences of using less effective soil fumigants in strawberry nurseries may be extensive (Larson and Shaw, 2000), and the impact of resistance breeding for lethal pathogens could provide an important aid for mitigating further losses (Shaw and Larson, 1999). Conversely, although trait mean differences between fumigation treatments increased over cultivation cycles, there was no trend in the fractional contribution of genetic $\times$ fumigation interaction variance. There seems no direct genetic solution within $F$. Xananassa to the yield and performance reductions that result from sublethal and competitive organisms, regardless of the number of nonfumigated crop cycles.

\section{Literature Cited}

Baker, R. 1988. Tests for crossover genotype-environment interactions. Can. J. Plant Sci. 68:405-410.

Burdon, R.D. 1977. Genetic correlation as a concept for studying genotype $\times$ environment interaction in forest tree breeding. Silvae Genet. 26:168-175.

Fernandez, G.C. 1992. Residual analysis and data transformations: Important tools in statistical analysis. HortScience 27:297-300.

Fort, S.B. and D.V. Shaw. 2000a. Genetic analysis of strawberry root

Table 5. Results for analysis of variance for seasonal strawberry yield and average fruit size, with one, two or three-four cycles of strawberry production preceding each nonfumigated treatment.

\begin{tabular}{|c|c|c|c|c|c|c|}
\hline \multirow[b]{3}{*}{ Source } & \multicolumn{6}{|c|}{ Mean squares } \\
\hline & \multicolumn{2}{|c|}{ Cycle 1} & \multicolumn{2}{|c|}{ Cycle 2} & \multicolumn{2}{|c|}{ Cycle 3-4 } \\
\hline & Yield $^{\mathrm{z}}$ & $\begin{array}{c}\text { Fruit } \\
\text { size }\end{array}$ & Yield & $\begin{array}{l}\text { Fruit } \\
\text { size }\end{array}$ & Yield & $\begin{array}{c}\text { Fruit } \\
\text { size }\end{array}$ \\
\hline Fumigation (F) & $4,668.8^{*}$ & 21.6 & $10,338.4^{* * *}$ & 3.4 & $7,356.4^{* * *}$ & $282.5^{* * *}$ \\
\hline $\operatorname{Rep} /(\mathrm{F})$ & $554.2^{* *}$ & $9.4^{* * *}$ & $112.5^{* *}$ & $6.1^{* *}$ & $84.3^{*}$ & $10.4^{* *}$ \\
\hline Genotype (G) & $317.2^{* * *}$ & $26.8^{* * *}$ & $180.4^{* *}$ & $28.5^{* *}$ & $312.3^{* *}$ & $27.8^{* *}$ \\
\hline $\mathrm{F} \times \mathrm{G}$ & 46.7 & 1.8 & 41.5 & 1.5 & 43.9 & $4.1^{*}$ \\
\hline Error & 46.8 & 1.6 & 24.1 & 1.5 & 36.1 & 2.4 \\
\hline$\sigma_{g}^{2}$ & 58.43 & 5.40 & 28.40 & 5.52 & 42.41 & 3.74 \\
\hline$\sigma_{f_{g}}^{2^{g}}$ & 0 & 0.05 & 7.14 & 0 & 2.44 & 0.55 \\
\hline$r_{\mathrm{gy}}^{\mathrm{fg}}$ & 1.0 & 0.99 & 0.80 & 1.0 & 0.96 & 0.87 \\
\hline $\mathrm{R}^{\mathrm{gy}}$ & 0.56 & 0.77 & 0.48 & 0.79 & 0.52 & 0.56 \\
\hline
\end{tabular}

${ }_{\mathrm{Z}}$ Mean squares and variance components for yield in thousands.

**** Significant at $P<0.05$ or 0.01 , respectively. 
system traits in fumigated and nonfumigated soils I. Inheritance patterns of strawberry root growth and performance characteristics. J. Amer. Soc. Hort. Sci. 125:318-323.

Fort, S.B. and D.V. Shaw. 2000b. Genetic analysis of strawberry root system traits in fumigated and nonfumigated soils II. Relationships among root system and above-ground traits of strawberry seedlings. J. Amer. Soc. Hort. Sci. 125:325-329.

Fort, S.B., D.V. Shaw, and K.D. Larson. 1996. Performance responses of strawberry seedlings to the sublethal effects of nonfumigated soils. J. Amer. Soc. Hort. Sci. 121:367-370.

Hancock, J., P. Callow, S. Serce, and A. Schilder. 2000. Relative performance of strawberry cultivars and Fragaria virginiana hybrids on fumigated and non-fumigated soil in Michigan. Hort Science (in press).

Larson, K.D. and D.V. Shaw. 1995. Relative performance of strawberry genotypes in fumigated and nonfumigated soil. J. Amer. Soc. Hort. Sci. 120:274-277.

Larson, K.D. and D.V. Shaw. 2000. Soil fumigation and runner plant production: A synthesis of four years of strawberry nursery field trials. HortScience 35:642-646.

SAS Institute, Inc. 1988. SAS/STAT users guide, release 6.03 ed. SAS Inst., Inc., Cary, N.C.

Shaw, D.V. 1992. Genetic correlations between vegetative growth traits and productivity at different within-season intervals for strawberries
(Fragaria $\times$ ananassa). Theor. Appl. Genet. 85:1001-1009.

Shaw, D.V. and K.D. Larson. 1996. Relative performance of strawberry cultivars from California and other North American sources in fumigated and nonfumigated soils. J. Amer. Soc. Hort. Sci. 121:764-767.

Shaw, D.V. and K.D. Larson. 1999. A meta-analysis of strawberry yield response to preplant soil fumigation with combinations of methyl bromide-chloropicrin and four alternative systems. HortScience 34:838-845.

Strand, L.L. 1994. Integrated pest management for strawberries. Univ. Calif. DANR Publ. 3351.

U.S. Department of Agriculture (USDA). 1993. Methyl bromide substitutes and alternatives. USDA, Wash., D.C.

Watson, R.T., D.L. Albritton, S.O. Anderson, and S.E. Bapty. 1992. Methyl bromide: Its atmospheric science, technology, and economics. Montreal Protocol Assessment Summary, United Nations Environment Program, Nairobi, Kenya.

Welch, N. 1989. Strawberry production in California. Univ. Calif. Coop. Ext. Lflt. 2959.

Wilhelm, S. and A.O. Paulus. 1980. How soil fumigation benefits the California strawberry industry. Plant Dis. 64:264-270.

Wilhelm, S., R.C. Storkan, and J.M. Wilhelm. 1974. Preplant soil fumigation with methyl bromide-chloropicrin mixtures for control of soil-borne diseases of strawberry-A summary of fifteen years of development. Agr. Environ. 1:227-236. 